http://jmscr.igmpublication.org/home/ ISSN (e)-2347-176x ISSN (p) 2455-0450

crossref DOI: https://dx.doi.org/10.18535/jmscr/v8i11.54

Journal Of Medical Science And Clinical Research

Original Research Article

\title{
Effects of Home-Based Pulmonary Rehabilitation on Six Minute Walk Distance in Patients with Chronic Obstructive Pulmonary Disease
}

\author{
Authors \\ Dr Vinayak Mohan ${ }^{1}$, Dr Manoj.D.K ${ }^{2}$, Dr.Rajani.M ${ }^{3 *}$, Dr Rishna Raveendran ${ }^{4}$, \\ Dr Pretty Radhakrishnan ${ }^{5}$ \\ ${ }^{1}$ Consultant Pulmonologist, Avitis Superspeciality Hospital, Nemmara \\ ${ }^{2}$ Professor \& HOD, Dept of Respiratory Medicine, GMC, Kannur \\ ${ }^{3}$ Professor, Dept of Respiratory Medicine, GMC, Kannur \\ 4,5 Junior Resident, GMC, Kannur \\ *Corresponding Author
}

Dr Rajani.M

\begin{abstract}
Background: COPD is an obstructive and progressive airway disease, and is also associated with a significant reduction in physical activity, and psychological problems. Pulmonary rehabilitation has been shown to be the most effective nonpharmacological intervention for improving health status in COPD patients and has become a standard of care for COPD patients.

Aim of this study was to determine the outcome of pulmonary rehabilitation in dyspnoea and exercise capacity in patient with Chronic obstructive pulmonary disease (COPD) using six minute walk test \& to determine the effect of pulmonary rehabilitation in the change in quality of life in patient with Chronic obstructive pulmonary disease (COPD).

Method: Patients were selected according to inclusion and exclusion criteria.. After complete clinical and relevant investigations. A six minute walk test was done on the same day. A St. George questionnaire was issued to the patient before initiation of rehabilitation. Patients are randomly classified into study group and control group. Patients underwent pulmonary rehabilitation program .Patients were advised to continue rehabilitation at home. A repeat 6 minute walk test was done after 12 weeks and the results was compared with his baseline distance. St George questionnaire was reissued and the results were compared.

Results: A sample of 40 patients were included. 6MWD decreases with increasing severity of the disease. $6 M W D$ increased significantly after rehabilitation for 12 weeks whereas no significant increase in $6 m w d$ was noted in control group. All four domains of st Georges respiratory questionnaire namely the symptom score, activity score, impact score and total score showed improvement. statistically significant improvement was established insymptom score and activity score.

Conclusion: Pulmonary rehabilitation has shown to be very effective in improving the exercise capacity, psychological problems and the overall quality of life.

Keywords: COPD. 6minute Walking Distance, Pulmonary Rehabilitation.
\end{abstract}




\section{Introduction}

COPD is an obstructive and progressive airway disease, and is also associated with a significant reduction in physical activity, and psychological problems, all of which contribute to the patient's disability and poor health-related quality of life ${ }^{(1)}$ COPD patients are disabled, the most significant systemic dysfunction in COPD patients being the peripheral muscle dysfunction resulting from both physical inactivity and systemic inflammation and other causes like hypoxemia, undernutrition, oxidative stress, and systemic corticosteroid therapy. Peripheral muscle dysfunction is related to pathophysiological changes in the skeletal muscle, namely reduced oxidative capacity with early lactic acidemia and oxidative stress ${ }^{(2-6)}$. COPD patients also have an increased risk of depression and anxiety which leads to further inactivity due to fear of breathlessness which consecutively leads to physical deconditioning. Exacerbations of COPD also causes the reduction of exercise performance, dyspnea, and the loss of health related quality of life (HRQoL). Integrated care principles are being adopted to optimize the management of these complex patients. Over the last few years, growing evidence of systemic manifestations in COPD patients and their negative effects on the functioning of these patients has accelerated the development and use of non pharmacological treatments, such as pulmonary rehabilitation (PR). PR and pharmacological therapy must work closely together, and gives a better outcome.

$\mathrm{PR}$ is the most effective non pharmacological intervention for improving health status in COPD patients and has become a standard of care for COPD patients ${ }^{(7)}$. Pulmonary rehabilitation initiated shortly after a hospitalization for a COPD exacerbation is clinically effective, safe, and associated with a reduction in subsequent hospital admissions. Measurement of exercise capacity is an integral element in assessment of patients with pulmonary disease. The usual test used for assessing change in exercise capacity are- a paced shuttle walk test and an un paced six minute walk test. A 6MWT is a powerful tool in the evaluation of functional status and prognosis of patients, with a variety of functional impairments. 6MWD test had proved to be reliable, inexpensive, safe, more reflective of activities of daily living, and easy to apply.

Our aim was To determine the outcome of pulmonary rehabilitation in dyspnoea and exercise capacity in patient with Chronic obstructive pulmonary disease (COPD) using six minute walk test \& To determine the effect of pulmonary rehabilitation in- the change in quality of life in patient with Chronic obstructive pulmonary disease (COPD).

\section{Materials and Methods}

This study was conducted at Department of Respiratory Medicine, Govt. Medical College KANNUR during March 2016-february 2017.

Study population wasPatients attending Department of respiratory medicine, Medical College Kannur those who were fulfilling the criteria for the diagnosis of COPD based on GOLD guidelines who satisfy the inclusion and exclusion criteria.

Sample size Sample size was calculated using the formula

Minimum sample size $\mathrm{n}=2(\mathrm{Z} 1-\mathrm{A} / 2+\mathrm{Z} 1-\mathrm{B} / 2) 2$

$\mathrm{X}$ (standard deviation) 2

(Effective size) 2

$20 \%$ is taken as lost follow up

$\mathrm{Z} 1-\mathrm{A} / 2$ corresponds to $5 \%$ level of significance

$\mathrm{Z} 1-\mathrm{B} / 2$ corresponds to $80 \%$ power

The values of standard deviation and effective size were calculated with respect to a similar study done by virendra singh et al in SMS medical college, Jaipur 58

Inclusion criteria COPD patients between 50-65 Who have not undergone any pulmonary rehabilitation programs till date were selected for the study. \& Willing and consented to participate in the study.

Exclusion Criteria: Patients with significant cardiac illness (unstable angina during the previous month or myocardial infarction during 
the previous month), A resting heart rate of $>120$ A systolic blood pressure of $>180 \mathrm{~mm} \mathrm{Hg}$ or A diastolic blood pressure of $>100 \mathrm{~mm} \mathrm{Hg}$, Patients with any neuromuscular disease or skeletal deformities (causing any kind of difficulty in walking), Patients with $\mathrm{Hb}<11 \mathrm{gm} \%$, Hemodynamic instability, Inability to co-operate /protect airway \& Other lung diseases.

We conducted a Randomized control study Department of Respiratory Medicine, govt medical college, Kannur, Pariyaram. Patients attending outpatient Satisfying inclusion

\section{Procedure}

Detailed history, general and systemic examination was done.vitals were checked and recordedOxygen saturation was noted with pulse oximeter. Chest $\mathrm{x}$-ray and spirometry was taken. (FEV1/FVC $<0.7$ is required to make a diagnosis of COPD and patients are classified according to severity of COPD) Routine blood investigations was done. ECG and echocardiogram was done. A six minute walk test was done on the same day. Data obtained is noted. Deviation from expected value calculated and recorded. A St. George questionnaire was issued to the patient to assess his quality of life before initiation of rehabilitation. Patients are randomly classified into study group and control group using lottery method. Patients underwent pulmonary rehabilitation program.

Pulmonary rehabilitation program include upper limb exercises, Lower limb exercises (walking; twice a day; submaximal speed;)- breathing exercise (purse lip breathing and diaphragmatic breathing exercise) \& chest physiotherapy (postural drainage), correction of inhalational techniques, diet modification, smoking cessation \&psychological support and counselling .Patients were advised to continue rehabilitation at home (Home rehabilitation is a useful, equivalent alternative to outpatient rehabilitation in patients with COPD). Each patient will be followed up after 2 weeks and is motivated and promoted to continue rehabilitation measures.
A repeat 6 minute walk test was done and the results were compared with their baseline distance after 12 weeks. St George questionnaire was reissued and the results were compared to assess the change in quality of life after pulmonary rehabilitation.

\section{Statistical Analysis}

Descriptive statistical tools like frequency, percentage, mean, and standard deviation, median will be used. Inferential statistical test like t-test, chi square test and Mann Whitney $U$ test will be used. $\mathrm{P}$ value of less than 0.05 will be considered significant

\section{Results Sex}

Both the rehabilitation group and the nonrehabilitation group contain 20 males patients each in the age group 51-64 year.

Table -1

\begin{tabular}{|l|r|c|c|}
\hline AGE & & & \\
\hline GROUP & $\mathbf{N}$ & Mean & Std. Deviation \\
\hline experimental group & 20 & 58.75 & 3.64 \\
\hline control group & 20 & 57 & 3.64 \\
\hline
\end{tabular}

\section{Figure-1}

\section{severity of airway obstruction}

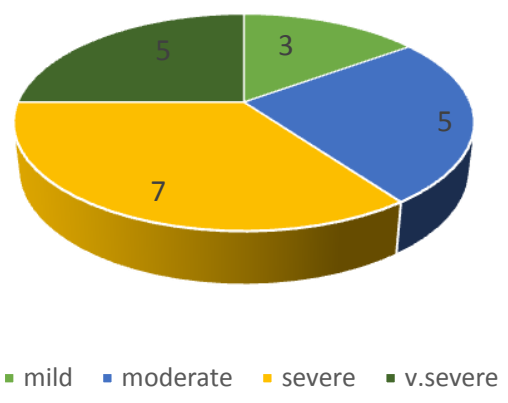

Both groups has same number in each group.

Smoking Index: All the patients had a smoking index of more than 500. The range of smoking index was between 500-1600. There was no statistical significance between smoking index and severity of COPD with $p$ value of 0.314 .

Six Minute Walk Distance Six minute walks distance decreases with increase in severity of COPD. The graph below shows the mean of 6MWD in patients belonging to each group. 
Table-2

\begin{tabular}{|c|c|c|c|c|}
\hline 6MWD 1 & & & & \\
\hline GROUP & N & Mean & $\begin{array}{c}\text { Std. } \\
\text { Deviation }\end{array}$ & p value \\
\hline experimental group & 20 & 245.75 & 62.43 & 0.823 \\
\cline { 1 - 4 } control group & 20 & 241.5 & 57.06 & \\
\hline
\end{tabular}

(Using Student's ttest)
Table-3

\begin{tabular}{|c|c|c|c|c|}
\hline 6MWD 2 & & & & \\
\hline GROUP & N & Mean & $\begin{array}{c}\text { Std. } \\
\text { Deviation }\end{array}$ & p value \\
\hline experimental group & 20 & 317 & 67.21 & $\mathbf{0 . 0 0 1}$ \\
\hline control group & 20 & 249 & 54.47 & \\
\hline
\end{tabular}

Figure 2: Six Minute walk Distance indifferent group of patients

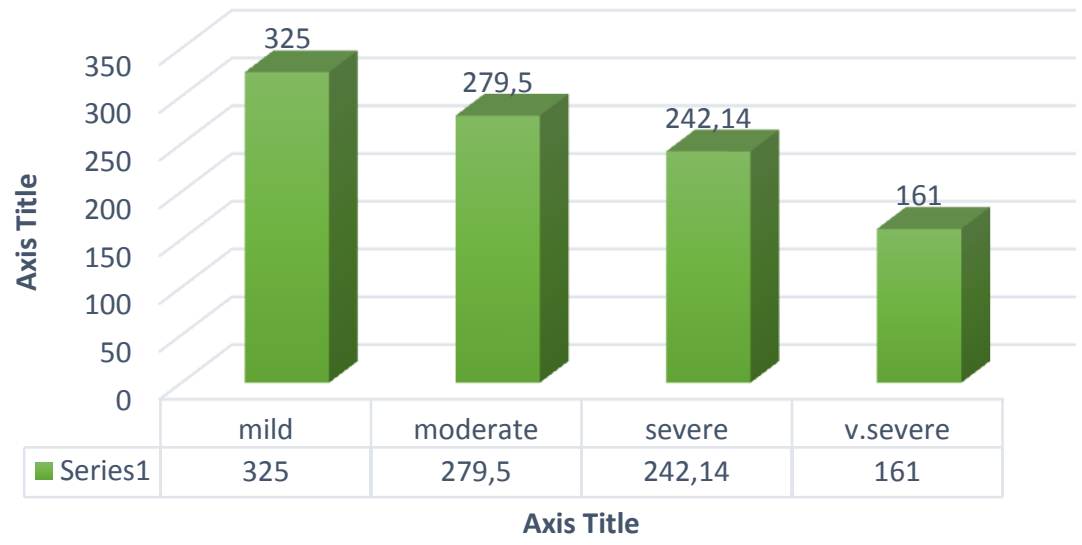

- Series1

When comparing the six minute walk distance of the same patients before and after the rehabilitation program there is statistically significant difference with a mean increase of 72 meters. This proves that pulmonary rehabilitation is effective against the progressive exercise limitation in COPD patients and it also helps to decrease the baseline breathlessness of the patients.
Experimental group who underwent three weeks of pulmonary rehabilitation showed an increase in approximately 73 meters whereas control group does not have significant increase in $6 \mathrm{MWD}$, which signifies the effectiveness of pulmonary rehabilitation in improving exercise capacity with $\mathrm{p}$ value of 0.001 .

\section{Figure-3}

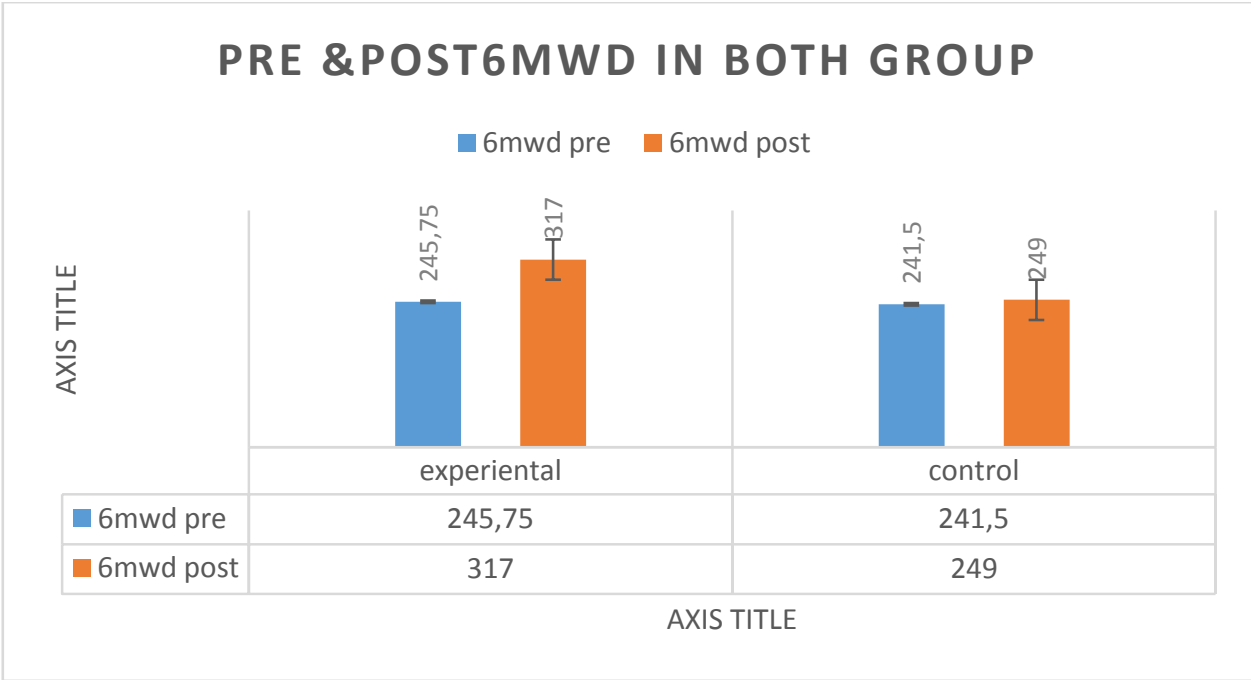




\section{Symptom Score (SGRQ-C): Statistically} analyzing the medians of the symptom score using mann whitney test, it is clear that ( $p$ value 0.030 ) symptoms of the patients who underwent rehabilitation is significantly decreased whereas patients have slightly progressive symptoms in the control group.

Activity Score SGRQ -C. Statistically analyzing the medians of either groups prove that the daily activity of the experimental group shows significant improvement ( $\mathrm{p}$ value 0.033 ) while the activities are decreased in non rehabitation group.

Impact Score SGRQ -C Analyzing the score there was no statistically significant reduction in the impact caused by the disease, although there was clinically significant reduction.

Total Score The overall score calculated shows that the rehabilitation group shows decrease in score where as non-rehabilitation group shows increase in the total score. But no statistical significance.

BORG Dyspnoea Score: It is a subjective scoring method to assess the severity of dyspnea, it is clear that in rehabilitation group there is a decrease in the baseline dyspnea but the nonrehabilitation group have similar baseline dyspnea with no improvement.

\section{Table-4}

\begin{tabular}{|c|c|c|c|c|}
\hline Variable & Statistic & $\begin{array}{c}\text { Experimental } \\
\text { group }\end{array}$ & $\begin{array}{c}\text { Control } \\
\text { group }\end{array}$ & P value \\
\hline \multirow[t]{6}{*}{ BORG } & Mean & 6.25 & 5.80 & \multirow[t]{6}{*}{0.262} \\
\hline & Median & 6.00 & 5.00 & \\
\hline & Std. Deviation & 1.55 & 1.70 & \\
\hline & Minimum & 4.00 & 4.00 & \\
\hline & Maximum & 9.00 & 9.00 & \\
\hline & Interquartile Range & 2.00 & 2.00 & \\
\hline \multirow[t]{6}{*}{ BORG_A } & Mean & 4.95 & 5.75 & \multirow[t]{6}{*}{0.091} \\
\hline & Median & 5.00 & 5.00 & \\
\hline & Std. Deviation & 1.00 & 1.52 & \\
\hline & Minimum & 4.00 & 4.00 & \\
\hline & Maximum & 7.00 & 9.00 & \\
\hline & Interquartile Range & 1.00 & 2.00 & \\
\hline \multirow[t]{6}{*}{ smoking index } & Mean & 750.00 & 815.00 & \multirow[t]{6}{*}{0.314} \\
\hline & Median & 750.00 & 800.00 & \\
\hline & Std. Deviation & 205.20 & 221.89 & \\
\hline & Minimum & 500.00 & 550.00 & \\
\hline & Maximum & 1200.00 & 1400.00 & \\
\hline & Interquartile Range & 275.00 & 250.00 & \\
\hline \multirow[t]{6}{*}{ symptom score } & Mean & 69.61 & 70.95 & \multirow[t]{6}{*}{0.989} \\
\hline & Median & 73.07 & 71.86 & \\
\hline & Std. Deviation & 15.29 & 14.99 & \\
\hline & Minimum & 37.50 & 46.94 & \\
\hline & Maximum & 97.05 & 97.05 & \\
\hline & Interquartile Range & 14.76 & 22.94 & \\
\hline \multirow[t]{5}{*}{$\begin{array}{l}\text { symptoms } \\
\text { score } 2\end{array}$} & Mean & 59.84 & 71.24 & \multirow[t]{5}{*}{0.030} \\
\hline & Median & 62.85 & 71.76 & \\
\hline & Std. Deviation & 14.58 & 14.64 & \\
\hline & Minimum & 23.52 & 48.18 & \\
\hline & Maximum & 85.19 & 95.09 & \\
\hline
\end{tabular}




\begin{tabular}{|c|c|c|c|c|}
\hline & Interquartile Range & 17.54 & 23.64 & \\
\hline \multirow[t]{6}{*}{ activity score } & Mean & 67.50 & 67.26 & \multirow[t]{6}{*}{0.862} \\
\hline & Median & 69.87 & 72.40 & \\
\hline & Std. Deviation & 15.51 & 16.01 & \\
\hline & Minimum & 42.32 & 37.50 & \\
\hline & Maximum & 92.45 & 92.45 & \\
\hline & Interquartile Range & 29.44 & 29.61 & \\
\hline \multirow[t]{5}{*}{ activity score 2} & Mean & 58.16 & 68.45 & \multirow[t]{5}{*}{0.033} \\
\hline & Median & 59.84 & 75.31 & \\
\hline & Std. Deviation & 14.00 & 16.10 & \\
\hline & Minimum & 29.86 & 42.32 & \\
\hline & Maximum & 83.55 & 97.40 & \\
\hline
\end{tabular}

Table 5

\begin{tabular}{|c|c|c|c|c|}
\hline Variable & Statistic & $\begin{array}{c}\text { Experime } \\
\text { ntal } \\
\text { group }\end{array}$ & $\begin{array}{c}\text { Control } \\
\text { group }\end{array}$ & P value \\
\hline \multirow[t]{6}{*}{ impact score } & Mean & 63.27 & 56.24 & \multirow[t]{6}{*}{0.301} \\
\hline & Median & 69.73 & 56.01 & \\
\hline & Std. Deviation & 18.67 & 19.32 & \\
\hline & Minimum & 24.70 & 22.59 & \\
\hline & Maximum & 89.97 & 83.58 & \\
\hline & Interquartile Range & 26.64 & 29.67 & \\
\hline \multirow[t]{6}{*}{ impact score 2} & Mean & 54.52 & 56.94 & \multirow[t]{6}{*}{0.698} \\
\hline & Median & 54.97 & 56.01 & \\
\hline & Std. Deviation & 18.06 & 19.34 & \\
\hline & Minimum & 22.89 & 22.59 & \\
\hline & Maximum & 83.58 & 82.39 & \\
\hline & Interquartile Range & 22.59 & 29.22 & \\
\hline \multirow[t]{6}{*}{ total score } & Mean & 66.17 & 62.18 & \multirow[t]{6}{*}{0.445} \\
\hline & Median & 71.83 & 63.38 & \\
\hline & Std. Deviation & 16.22 & 17.69 & \\
\hline & Minimum & 37.95 & 30.06 & \\
\hline & Maximum & 91.54 & 87.69 & \\
\hline & Interquartile Range & 26.99 & 29.36 & \\
\hline \multirow[t]{6}{*}{ total score 2} & Mean & 56.75 & 62.63 & \multirow[t]{6}{*}{0.221} \\
\hline & Median & 55.95 & 64.69 & \\
\hline & Std. Deviation & 16.58 & 18.34 & \\
\hline & Minimum & 25.14 & 27.78 & \\
\hline & Maximum & 81.71 & 89.77 & \\
\hline & Interquartile Range & 25.06 & 29.11 & \\
\hline
\end{tabular}

(Using Mann Whitney test for medians)

\section{Discussion}

The effectiveness of pulmonary rehabilitation in improving exercise capacity and health related quality of life has been established to be beneficial by many other previous studies. In our study the age group ranges from 51-64years and all of them where male, this is due to the fact that smoking is more common in male than in females in our locality. And being a tertiary center most of the patients were referred from local hospitals and the most common group was severe COPD (according to GOLD 2017). In our study we found that all of 
our patients had a smoking index more than 500, which ranges from $500-1500$, and there was no clear association between smoking index and severity of COPD. Development of COPD not only depends on smoking but also depends on many other factors like genetic factors environmental factors and host factors. The six minute walk distance decreases with increase in severity of the disease, which was clearly shown in our study. This result is almost consistent with study by Barbara Vagagginietal and Jingjuan Xum et al ${ }^{(9,10)}$. Considering the hindering factors for pulmonary rehabilitation in our locality mainly geography, culture, financial issues, Transport and other logistics we preferred home based rehabilitation with the help of family members, reliable bystanders or home nurses. A randomized control trial done by François maltis et al concludes that home rehabilitation is a useful, equivalent alternative to outpatient rehabilitation in patients with copd ${ }^{(11)}$. A study done by Boxall et al states that to manage COPD in community more effectively, health services should focus on expanding home -based pulmonary rehabilitation $^{(12)}$ In our study we have two groups the experimental group or the rehabilitation group and the control group or the non-rehabilitation group. The patients were grouped randomly and we used lottery method for grouping. In the rehabilitation group we found that exercise capacity was increased after 12 weeks of rehabilitation. There was a mean difference from (Mean+SD) 245.75. +62.43 meters pre rehabilitation to (Mean+SD) $317+67.21$ meters after rehabilitation. This result was similar to study done by Cheng ST et al (13) where they concluded that Exercise tolerance measured by 6MWT and dyspnea level determined through MMRC were significantly improved after 12 weeks of modified PR.A study by Altenburg et al. demonstrated that four variables are correlated with an improvement in endurance exercise capacity after 7 weeks of exercise in patients with $\operatorname{COPD}^{(14)}$.
In an evidence-based review of the literature surrounding treatment strategies for patients with COPD, pulmonary rehabilitation including at least 4 weeks of exercise training is shown to cause clinically and statistically significant improvements in health related quality of life (HRQOL) in patients with COPD and pulmonary rehabilitation also leads to a clinically and statistically significant improvement in functional exercise capacity Jingjuan $\mathrm{Xu}$ et al, states that 6MWT [(372.089 \pm 67.149$) \mathrm{m}]$ was significantly improved in the PR group $(\mathrm{P}<0.05)$ but was not significantly different in the control group $(\mathrm{P}>$ $0.05)$. MMRC) was significantly reduced in the $\mathrm{PR}$ group $(\mathrm{P}<0.05)$ but not in the control group $(\mathrm{P}>0.05)$. And concludes that Modified PR reduces the symptoms of dyspnea, increases exercise capacity, and improves the quality of life of patients with moderate to severe COPD $^{(15)} \mathrm{We}$ assessed the change in quality of life before and after pulmonary rehabilitation using st George respiratory questionnaire (SGRQ-C). All 4 domains of SGRQ showed improvement when compared after 12 weeks of rehabilitation program, control group showed no improvement in any of the domains, some patients in control group had worsening of the score showing the deterioration of quality of life after 3 months. Our result was similar to study done by jones pw et al which concluded that there were significant improvements in all domains of SGRQ (all

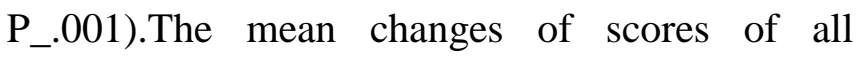
domains were more that 4 units, which was associated with clinical importance. (16).Surya Kant et al also confirmed that the SGRQsymptoms score improved (Mean+SD) $19.14+6.60$ in patients receiving pulmonary rehabilitation program, as compared to patients in control group (Mean+SD) 3.00+4.13 who were receiving standard medical treatment (SMT) only. The SGRQ-symptoms score in patients receiving pulmonary rehabilitation programs + Standard Medical treatment, when compared after rehabilitation program was significantly greater 
$(\mathrm{p}=0.001)$ than (patients receiving only standard medical treatment. ${ }^{(17)}$

\section{Conclusion}

Chronic obstructive pulmonary disease is a progressive disorder which Declines the quality of life of patients with increasing symptoms, recurrent Hospitalisations, economical burden, anxiety and depression. It is also associated with A significant reduction in physical activity, and psychological problems, all of which Contribute to the patient's disability and poor health-related quality of life (hrqol). Pulmonary rehabilitation has shown to be very effective in improving the Exercise capacity, psychological problems and the overall quality of life. it is as important as the pharmacological therapy. Pulmonary rehabilitation should be offered to all copd patients along with regular medications. Treatment of copd should be Considered incomplete without pulmonary rehabilitation.

\section{Limitation of our Study}

Small sample size. Single centered study. The intervention for the PR group lasted only 12 weeks. As a result, the long term effect of PR on patients with COPD was not observed. Furthermore, a real-time heart rate and degree of blood oxygen saturation were not collected during the intervention.

\section{References}

1. Vestbo J, Hurd SS, Agustí AG, et al. Global strategy for the diagnosis, management, and prevention of chronic obstructive pulmonary disease: GOLD executive summary. Am J Respir Crit Care Med.2013;187(4): 347-365.

2. American Thoracic Society; European Respiratory Society. Skeletal muscle dysfunction in chronic obstructive pulmonary disease. A statement ofthe American Thoracic Society and European Respiratory Society. Am J RespirCrit Care Med. 1999;159(4 Pt2):S1-S40.
3. Wüst RC, DegensH. Factors contributing to muscle wasting and dysfunction in COPD patients. Int $\mathrm{J}$ Chron Obstruct PulmonDis.2007;2(3):289-300.

4. Barreiro E, Gea J, Corominas JM, Hussain SN. Nitric oxide syntheses and protein oxidation in the quadriceps femoris of patients withchronic obstructive pulmonary disease. Am J Respir Cell MolBiol. 2003;29(6):771-778.

5. GoskerHR, HesselinkMK, DuimelH, Ward KA, Schols AM. Reduced mitochondrial density in the vastuslateralis muscle of patients with COPD. EurRespir J.2007;30 (1):73-79.

6. Maltais F, Simard AA, Simard C, Jobin J, Desgagnés $\mathrm{P}$, LeBlanc $\mathrm{P}$. Oxidative capacity of the skeletal muscle and lactic acid kinetics during exercise in normal subjects and in patients with COPD. Am J Respir Crit Care Med. 1996;153(1):288293.

7. Agusti A, Soriano JB. COPD as a systemic disease. COPD. 2008;5(2):133138.

8. Pulmonary Rehabilitation In Patients With Chronic Obstructive Pulmonary Disease Virendra Singh et al ; Indian Jounal Of Chest Diseases Allied Sciences 2003; Vol 45;P13-17

9. Barbara Vagaggini et al Clinical predictors of the efficacy of a pulmonary rehabilitation programme in patients with COPD Ann Intern Med 2012;156(10): 673-83.

10. Vogiatzis I, Rochester CL, Spruit MA, Troosters T, Clini EM, American Thoracic Society/European Respiratory Society Task Force on Policy in Pulmonary Rehabilitation. Increasing implementation and delivery of pulmonary rehabilitation: key messages from the new ATS/ERS policy statement. Eur Respir J2016; 47(5):1336-41.

11. Effects of Home-Based Pulmonary 
Rehabilitation in Patients with Chronic Obstructive Pulmonary Disease: A Randomized Trial François Maltais et al;

12. Annals Of Interenal Medicine; December 2008; Vol 149,No12Managing Chronic Obstructive Pulmonary Disease in the Community: A Randomized Controlled Trial Of Home-Based Pulmonary Rehabilitation For Elderly Housebound Patients; Boxall et al journal of cardiopulmonary rehabilitation vol-25 issue-6p378-385

13. Cheng ST, Wu YK, Yang MC, Huang CY, Huang $\mathrm{HC}$, Chu WH, et al. Pulmonary rehabilitation improves heart rate variability at peak exercise, exercise capacity and health-related quality of life in chronic obstructive pulmonary disease. Heart Lung2014;43(3):249e55

14. Altenburg WA, de Greef MH, ten Hacken $\mathrm{NH}$, Wempe JB. A better response in exercise capacity after pulmonary rehabilitation in more severe COPD patients. Respir Med 2012;106(5):694e700

15. Jingjuan $\mathrm{Xu}$ et al Effects of modified pulmonary rehabilitation on patients with moderate to severe chronic obstructive pulmonary disease: A randomized controlled trail

16. Rochester CL, Vogiatzis I, Holland AE, et al. An Official American Thoracic Society/European Respiratory Society Policy Statement: Enhancing Implementation, Use, and Delivery of Pulmonary Rehabilitation. Am J Respir Crit Care Med 2015; 192(11):1373-86.

17. Surya Kant, Rakesh Kumar, Tariq Mahmood, Alok Chandra, A. K. Verma, Ravi Bhaskar Journal of Evolution of Medical and Dental Sciences/ Volume 2/ Issue 10/ March 112013 Page-1496. 